\title{
Solid biofuels production from agricultural residues and processing by-products by means of torrefaction treatment: the case of sunflower chain
}

\author{
Daniele Duca, Giovanni Riva, Ester Foppa Pedretti, Giuseppe Toscano, Chiara Mengarelli, \\ Giorgio Rossini
} Dipartimento di Scienze Agrarie, Alimentari e Ambientali, Università Politecnica delle Marche,
Ancona, Italy

\begin{abstract}
The high heterogeneity of some residual biomasses makes rather difficult their energy use. Their standardisation is going to be a key aspect to get good quality biofuels from those residues. Torrefaction is an interesting process to improve the physical and chemical properties of lignocellulosic biomasses and to achieve standardisation. In the present study torrefaction has been employed on residues and by-products deriving from sunflower production chain, in particular sunflower stalks, husks and oil press cake. The thermal behaviour of these materials has been studied at first by thermogravimetric analysis in order to identify torrefaction temperatures range. Afterwards, different residence time and torrefaction temperatures have been tested in a bench top torrefaction reactor. Analyses of raw and torrefied materials have been carried out to assess the influence of the treatment. As a consequence of torrefaction, the carbon and ash contents increase while the volatilisation range reduces making the material more stable and standardised. Mass yield, energy yield and energy densification reach values of about $60 \%$, $80 \%$ and 1.33 for sunflower stalks and 64\%, 85\% and 1.33 for sunflower oil press cake respectively. As highlighted by the results, torrefaction is more interesting for sunflower stalks than oil cake and husks due to their different original characteristics. Untreated oil press cake and husks, in fact, already show a good high heating value and, for this reason, their torrefaction should be mild to avoid an excessive ash concentration. On the contrary, for sunflower stalks the treatment is more useful and could be more severe.
\end{abstract}

Correspondence: Giorgio Rossini, Dipartimento di Scienze Agrarie, Alimentari e Ambientali (D3A), Università Politecnica delle Marche, via Brecce Bianche, 60131 Ancona, Italy.

Tel.: +39.0712204297 - Fax: +39.0712204167

E-mail: g.rossini@univpm.it

Key words: husks, oil press cake, stalks, sunflower residues, torrefaction.

Received for publication: 1 July 2014

Accepted for publication: 2 August 2014.

(C) Copyright D. Duca et al., 2014

Licensee PAGEPress, Italy

Journal of Agricultural Engineering 2014; XLV:416

doi:10.4081/jae.2014.416

This article is distributed under the terms of the Creative Commons Attribution Noncommercial License (by-nc 3.0) which permits any noncommercial use, distribution, and reproduction in any medium, provided the original author(s) and source are credited.

\section{Introduction}

Solid biomasses usually have different physical and chemical properties making them difficult to use in combustion systems (Virmond $e t$ al., 2012; Wu et al., 2011, Jenkins et al., 1998). The main critical aspects are the high moisture content, the heterogeneity of the inorganic fraction and the variability of the organic components. For this reason specific treatments have been studied and developed in order to obtain more homogeneous and standard biofuels. In particular there is a great interest in the torrefaction process due to its energy efficiency as well as the related advantages at a qualitative level (Van der Stelt et al., 2011; Uslu et al., 2008). Torrefaction is a thermo-chemical process, similar to a mild pyrolysis, to be performed on lignocellulosic biomass under an inert atmosphere, such as nitrogen. During torrefaction the biomass is treated at a relatively mild temperature in order to break the chemical bonds of the organic molecules, mainly cellulose, hemi-cellulose and lignin. As a consequence, the changes of the biomass structure produce a high-energy concentrated solid torrefied together with a volatile and a liquid compound. This process causes in wood, and generally in ligno-cellulosic materials, interesting changes for combustion purposes such as: the increase in energy density, the decrease in hygroscopicity and the ease of grinding (Arias et $a l ., 2008)$. There are also benefits in terms of biological stabilisation and cost reduction for the biomass transport and storage. Other authors also verified the possibility to mix the torrefied product with coal for the supply of power plants (Li et al., 2012). In general terms, the behaviour of the torrefied product is similar to that of a traditional solid fossil fuel (Chen and Kuo, 2010).

Torrefaction is a thermal pre-treatment of a solid biomass run without oxygen, at atmospheric pressure and at temperatures between 200 and $300^{\circ} \mathrm{C}$. The first effect on the material is the removal of moisture content and the increase of net calorific value. The process determines a loss of solid matter by volatilisation up to $30 \%$ by weight, leading inevitably to a loss of energy up to $15 \%$. The lower energy loss, with respect of the mass loss, is explained by the higher decrease of the oxygen atoms and partly of the hydrogen atoms compared to the decrease of the carbon atoms during the process. Energy and mass balances are therefore key factors for the evaluation of the torrefaction process (Chen et al., 2011). The loss of hydroxyl groups, particularly in wood, but in general in all ligno-cellulosic matrices, is also responsible of a lower hygroscopy of the torrefied materials if compared with the untreated materials.

The present work was carried out within the Extravalore project, funded by MIPAAF (the Italian Ministry of Agricultural, Food and Forestry Policies), about the valorisation of by-products deriving from the biodiesel production process. The present paper aims in particular to find a possible valorisation of sunflower chain residues. The tor- 
refaction of the sunflower stalks and the oil press cake has therefore been studied in order to evaluate the characteristics and the behaviour of the torrefied obtained as well as to assess the advantages for energy applications of these different starting materials.

\section{Materials and methods}

\section{Introduction}

Materials were obtained within the Extravalore project from seeds and residues of sunflowers cultivated in 0simo (Marche region) and then processed in the Biomass Lab of D3A Department of Università Politecnica delle Marche.

The experimental work was performed as follows: i) sample preparation; ii) thermogravimetric analysis to define the torrefaction temperatures (Tts) for the later tests in the reactor; iii) torrefaction tests; iv) characterisation of raw and torrefied materials by thermogravimetric, proximate and ultimate analyses.

The steps are described in details below.

\section{Sample preparation}

Here is a list of the materials employed in the present study and their respective moisture contents at sampling: i) sunflower stalks: 18.0\%; ii) sunflower press cake: 9.7\%; iii) sunflower husks: $6.7 \%$.

These materials were dried at $105^{\circ} \mathrm{C}$ overnight in a forced ventilation oven [MPM Instruments srl, Bernareggio (MI), Italy], then grinded in a cutting mill (RETSCH, Haan, Germany) to a particle size $\leq 2$ $\mathrm{mm}$. All materials, both the raw and the processed ones, were stored in air-tight plastic containers at room temperature until analyses were carried out.

\section{Thermogravimetric analysis}

The thermal behaviour of the raw and the torrefied biomasses was studied by means of thermogravimetric analysis, carried out with a thermogravimetric analyser (Linseis Inc., Robbinsville, NJ, USA). The weight loss trend, recorded by that instrument depending on the temperature and the time increase, represents the thermogravimetric curve (TG). Moreover, processing the TG function to obtain its first derivative thermogravimetric curve (DTG), it is possible to get more information about the thermal degradation kinetics and, as a consequence, of the lignocellulosic composition of the biomass. For all the experimental runs, $20 \mathrm{mg}$ of each material were heated from ambient temperature up to $700^{\circ} \mathrm{C}$ in an inert atmosphere. Nitrogen at $100 \mathrm{~cm}^{3}$ $\mathrm{min}^{-1}$ flow rate was used to keep the environment inert. The first analyses were made on the original materials at $5^{\circ} \mathrm{C} \mathrm{min}^{-1}$ heating rate to define the torrefaction temperatures to be tested in the reactor. This rate has been used to allow a more homogeneous sample heating, as reported by some authors (Grønli et al., 2002), and to simulate the heating rate of the reactor as well. By means of DTG results the Tts for the tests in the torrefaction reactor were defined. At a later stage, TGs of torrefied and raw materials were carried out to observe the influence of torrefaction conditions on material structure. A faster heating rate $\left(20^{\circ} \mathrm{C} \mathrm{min}-1\right)$, still in an inert atmosphere, was performed in order to reduce the analytical time. To evaluate the experimental reproducibility, each sample was analysed for three times and the DTGs obtained were almost superimposable.

\section{Torrefaction tests}

Torrefaction was carried out in a heated bench-top reactor. The sample $(10 \mathrm{~g})$ was placed in a sample holder and located in the centre of the reactor chamber in order to avoid the direct contact between the biomass and the hot reactor walls. Each test was performed with flowing nitrogen gas to maintain an inert environment inside the reactor. Temperature was controlled during the test using a PID controller. The temperature program consists of a slow heating rate $\left(5^{\circ} \mathrm{C} \mathrm{min}-1\right)$ from ambient temperature up to $\mathrm{Tt}$, followed by an isothermal step defined as residence time (Rt). The sample was then cooled to room temperature by a water cooling system and under a continuous nitrogen flow through the reactor. The solid torrefied was then weighted and collected for further analyses. For each material different Tts and Rts were tested to evaluate the torrefaction effects. Each test was performed in triplicate. Tts were chosen for each material referring to its own DTG profile at $5^{\circ} \mathrm{C} \mathrm{min}-1$. More in detail, 3 temperatures to be tested by the reactor were selected within the reactivity range of hemicelluloses, defined as the range between the initial degradation temperature $\left(\mathrm{T}_{\text {onset }}\right)$ and the maximum degradation rate temperature $\left(\mathrm{T}_{\text {shoulder }}\right)$. This range was equally divided into three parts, and the selected Tts are reported in Table 1. Sunflower husks were not tested by the torrefaction process because their energy characterisation gave interesting results and the pre-treatment would not be so useful.

\section{Heating value, proximate and ultimate analyses of materials}

To evaluate the influence of the torrefaction conditions on biomass quality, raw and torrefied biomass were analysed. Heating value, proximate and ultimate analyses were performed for all materials in accordance with the European standards, as summarised in Table 2.

Process parameters were calculated to evaluate how temperature and time of the torrefaction treatment influence biomass quality and composition according to the following equations:

$$
\begin{aligned}
& \mathrm{Y}_{\mathrm{m}}(\%)=\left(\mathrm{m}_{\text {tor }} / \mathrm{m}_{\text {bio }}\right) \cdot 100 \\
& \mathrm{I}_{\text {ed }}=\mathrm{LHV}_{\text {tor }} / \mathrm{LHV}_{\text {bio }} \\
& \mathrm{Y}_{\mathrm{E}}(\%)=\mathrm{Y}_{\mathrm{m}} \cdot \mathrm{I}_{\text {ed }}
\end{aligned}
$$

where $Y_{m}$ and $Y_{E}$ are mass and energy yields and represent the amount of matter and energy remained after the process; $I_{e d}$ is the energy densification index which represents the increasing of the energy contained in the material; $m$ is the mass of the material, and $L H V$ is the lower heating value. Subscripts tor and bio refers to torrefied and raw biomass respectively. All parameters are expressed on dry ash-free base (daf). Taking into account the results of elemental analysis, hydrogen $(\mathrm{H}) /$ carbon $(\mathrm{C})$ and oxygen $(0) / \mathrm{C}$ atomic ratios were calculated and plotted in a van Krevelen diagram.

Table 1. Operative setting parameters used for the tested materials.

\begin{tabular}{lccr}
$\begin{array}{c}\text { Sunflower stalks } \\
\text { Temperature } \\
\left({ }^{\circ} \mathrm{C}\right)\end{array}$ & $\begin{array}{c}\text { Sunflower cake } \\
(\mathrm{min})\end{array}$ & $\begin{array}{c}\text { Temperature } \\
\left({ }^{\circ} \mathrm{C}\right)\end{array}$ & $\begin{array}{r}\text { Time } \\
(\mathrm{min})\end{array}$ \\
195 & 30 & 200 & 30 \\
& 60 & & 60 \\
215 & 30 & 230 & 30 \\
& 60 & & 60 \\
\hline 235 & 30 & 260 & 30 \\
& 60 & & 60 \\
\hline
\end{tabular}




\section{Results and discussion}

\section{Thermogravimetric analysis}

The results of thermogravimetric analyses carried out on the starting materials are reported below. The sunflower stalks produce DTG curves showing a clear overlap of the peak of hemicelluloses with that of cellulose (Figure 1). Unlike classical ligno-cellulosic biomasses the kinetics of thermal degradation is rather low, especially regarding celluloses.

It can also be noted a certain diversity of response among the 3 repetitions. This is related, most likely, to the heterogeneity of the material. The stalks, in fact, consist of two main components, a cortex and a marrow, with different specific weights that are difficult to mix after grinding, and consequently make also difficult the test sample homogenisation.

The $\mathrm{T}_{\text {onset }}$ of this material is about $180-190^{\circ} \mathrm{C}$ and the $\mathrm{T}_{\text {shoulder }}$ about $240-250^{\circ} \mathrm{C}$. For sunflower stalks were selected a Tmin and Tmax close, respectively, to the point of onset and shoulder $\left(\operatorname{Tmin}=195^{\circ} \mathrm{C}\right.$, $\left.\operatorname{Tmax}=235^{\circ} \mathrm{C}\right)$, and a Tint in the centre $\left(215^{\circ} \mathrm{C}\right)$.

The sunflower cake cannot be considered as a classic lignocellulosic biomass since surely it also consists of a fatty component. Residual oil deriving from the mechanical pressing of seeds in fact still remains inevitably trapped within the matrix of the cake in a variable percentage.

Looking at the thermal profile obtained from the TG analysis (TGA) (Figure 2) at least one peak more, with respect to classic lignocellulosic biomass, is observed. That peak corresponds to the volatilisation of the oil and reaches its maximum degradation kinetic at a temperature of about $375^{\circ} \mathrm{C}$.

On the whole, the kinetic of degradation does not reach high values. The first peak that is encountered, probably associated with the decomposition of the hemicellulose fraction, is the lower and the more on the left.

For this product 3 temperatures included in the range of holocelluloses degradation were chosen: $200^{\circ} \mathrm{C}, 230^{\circ} \mathrm{C}$ and $260^{\circ} \mathrm{C}$.

The thermal profile obtained from the TGA of sunflower husks (Figure 3) shows a clear overlap of the peak of hemicelluloses with that of cellulose. The highest cellulose degradation rate is reached at about $340^{\circ} \mathrm{C}$, a rather high temperature with respect to the other materials tested. However the degradation kinetics are higher. This behaviour is typical of woody material.

\section{Results of torrefaction tests and characterisation of raw and torrefied materials}

The results of chemical and energetic analyses of raw and torrefied samples are listed as follows.

The results of the characterisation of the torrefied sunflower stalks as well as the related process yields are shown in Table 3 .

While the calorific value and the energy concentration index show an increase, the mass yield and the energy yield confirm the usual downward trend, reaching values of $60 \%$ and $80 \%$ respectively at the most critical conditions.

The main results obtained by the treatment of sunflower stalks at different operating conditions are also shown in a graphic form (Figures 4 and 5).

Table 4 shows the results obtained from the analysis of torrefied sunflower cake: similarly to what observed for the other biomasses, a more severe torrefaction, in terms of temperature and/or residence time, leads to an increase in carbon content and heating value and, in parallel, to a reduction in mass yield and energy yield.

Figures 6 and 7 show in a graphic form the trend of the mass yield,

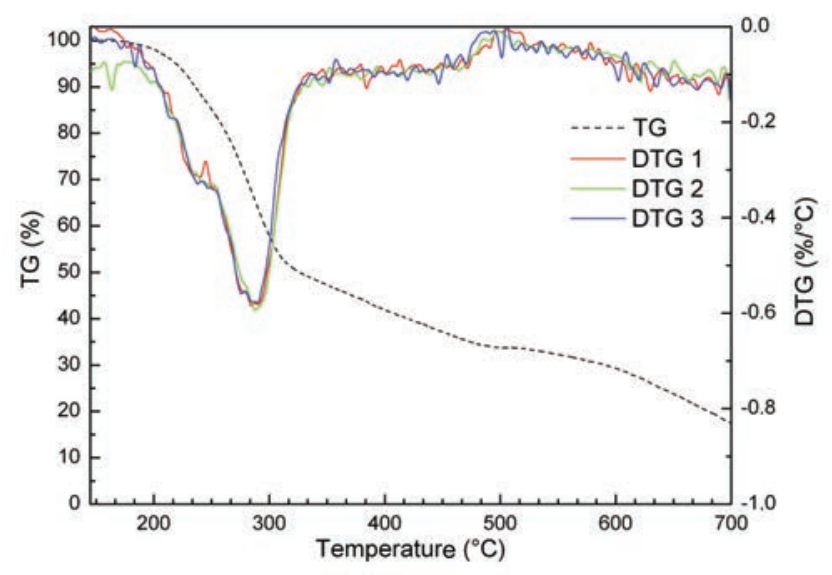

Figure 1. Curves produced from the thermogravimetric (TG) analysis of sunflower stalks. Overlapping of three repetitions. DTG, derivative TG curve.

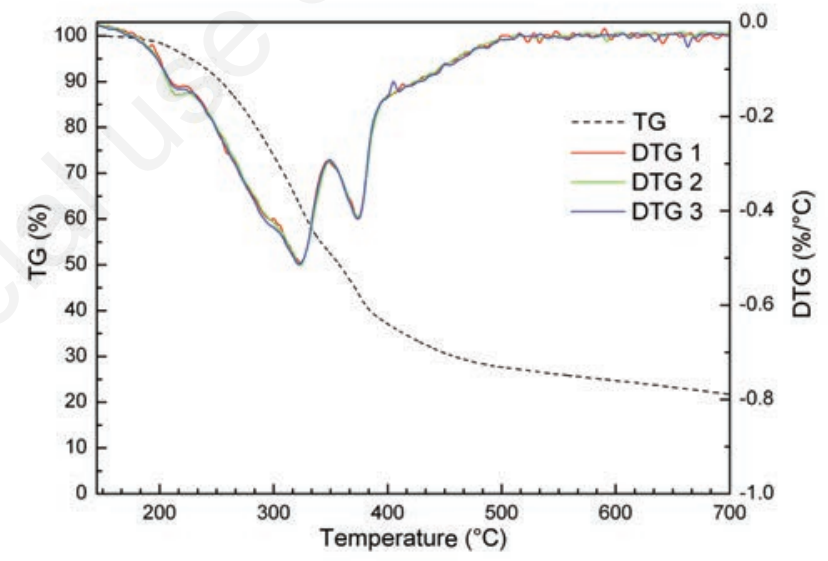

Figure 2. Curves produced from the thermogravimetric (TG) analysis of sunflower cake. Overlapping of results of three repetitions. DTG, derivative TG curve.

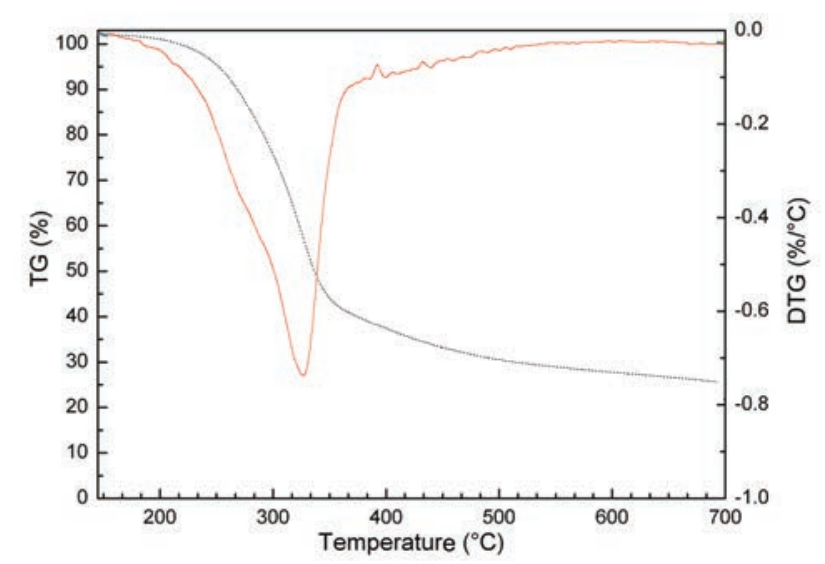

Figure 3. Curves produced from the thermogravimetric (TG) analysis of sunflower husks. DTG, derivative TG curve. 
Table 2. European standards and instruments employed for heating value, proximate and ultimate analyses.

\begin{tabular}{lcc} 
Operation/analysis & Method & Instrument \\
Sample preparation & UNI EN 14780 & Grinder mill \\
Moisture content & UNI EN 14774 & Stove at T $=105^{\circ} \mathrm{C}$ - Thermogravimetric scale \\
\hline Ash content & UNI EN 14775 & Muffle at T $=550^{\circ} \mathrm{C}$ - Thermogravimetric scale \\
$\mathrm{C}, \mathrm{H}, \mathrm{N}, \mathrm{O}$ & UNI EN 15104 & Elemental analyser \\
\hline High heating value & UNI EN 14918 & Calorimeter \\
Lower heating value & UNI EN 14918 & Calorimeter - Elemental analyser \\
\hline Thermogravimetric profile & Internal method & Thermogravimetric analyser \\
\hline
\end{tabular}

Table 3. Sunflower stalks: analysis of torrefied products. Each torrefaction condition was tested in triplicate and the mean results are shown in the respective rows. Moreover, every parameter was analysed for each torrefied sample in duplicate (a third analysis repetition was not possible due to the small amount of sample available).

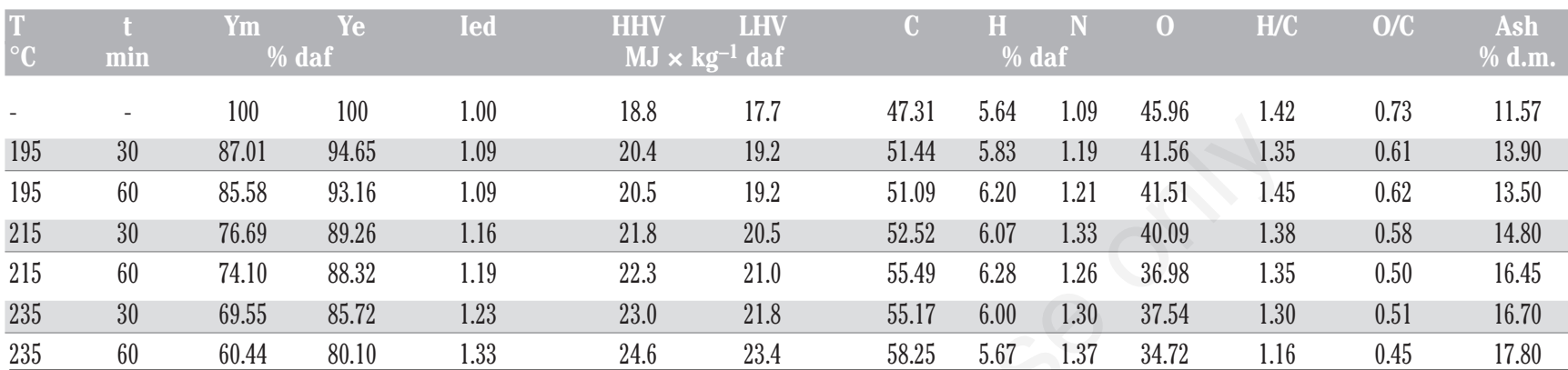

T, temperature; t, time; Ym, mass yields; Ye, energy yields; led, energy densification index; HHV, higher heating value; LHV, lower heating value; $\mathrm{C}$, carbon; $\mathrm{H}$, hydrogen; $\mathrm{N}$, nitrogen; $\mathrm{O}$, oxygen; $\mathrm{H} / \mathrm{C}$, hydrogen/carbon atomic ratio; $\mathrm{O} / \mathrm{C}$, oxygen/carbon atomic ratio.

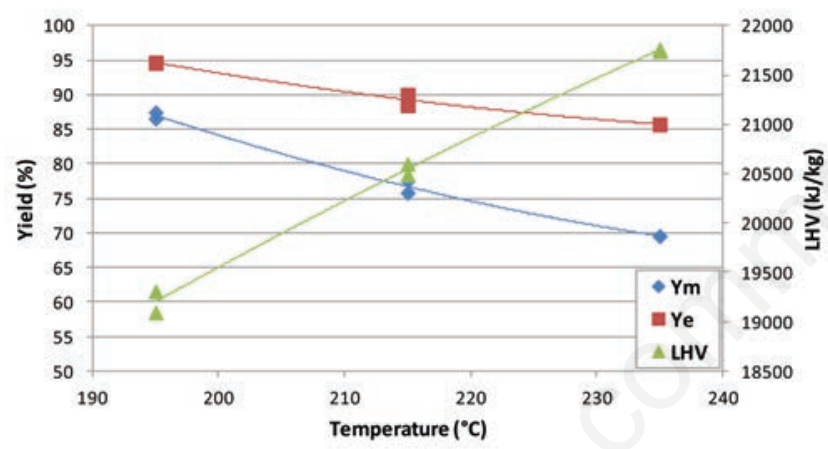

Figure 4. Performance of the process yields as a function of temperature [mass yields (Ym), and energy yields (Ye)] and lower heating value (LHV) trend of the 30 min torrefied sunflower stalks samples.

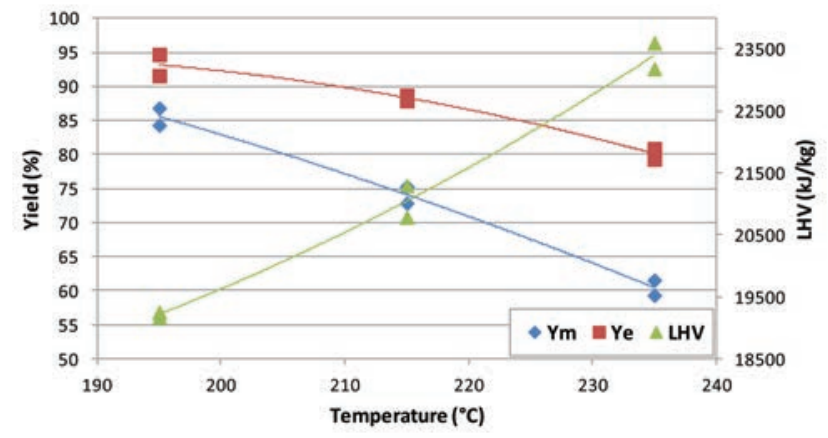

Figure 5. Performance of the process yields depending on the temperature [mass yields $(\mathrm{Ym})$, and energy yields (Ye)] and lower heating value (LHV) trend of the $60 \mathrm{~min}$ torrefied sunflower stalks samples.

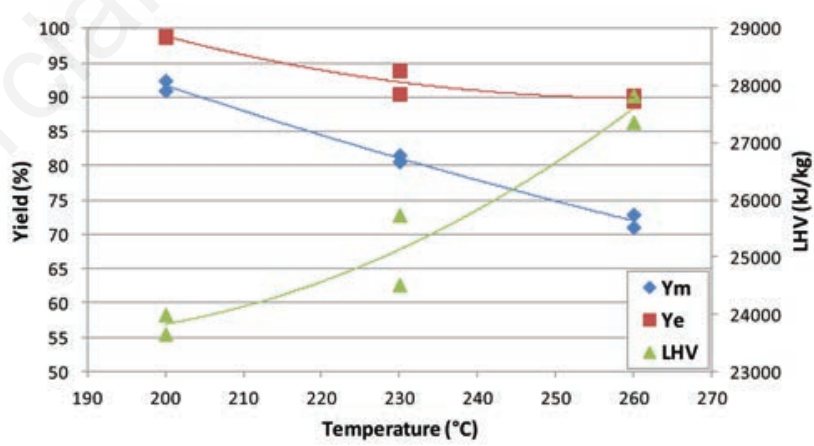

Figure 6. Performance of the process yields as a function of the temperature [mass yields (Ym), and energy yields (Ye)] and the related lower heating value (LHV) trend for the samples of torrefied sunflower cake obtained at $\mathbf{3 0} \mathrm{min}$ residence time.

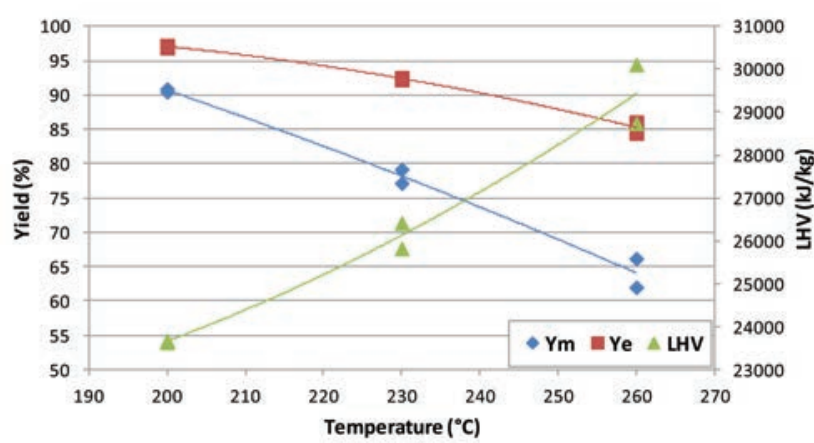

Figure 7. Performance of the process yields as a function of the temperature [mass yields ( $\mathrm{Ym})$, and energy yields (Ye)] and the related lower heating value (LHV) trend of the torrefied sunflower cake samples obtained at $\mathbf{6 0}$ min residence time. 
the energy yield and the lower heating value depending on the different torrefaction temperatures tested for a residence time of 30 and $60 \mathrm{~min}$ respectively. The results of chemical and energetic analyses carried out on sunflower husks are reported in Table 5.

Untreated sunflower husk is an interesting material for energy application due to its high energy content as well as its limited nitrogen and ash content. The most important limit of such biomass is, actually, the poor bulk density that cannot be solved by torrefaction but rather by a mass densification process, such as pelletisation.

\section{van Krevelen diagram about sunflower stalks and cake}

The torrefaction treatment determines changes in the organic structure of all biomasses. In all cases an increase in the concentration of $\mathrm{C}$, associated with a decrease of the 0 content, was observed. On the other hand the concentration of $\mathrm{H}$ oscillates without showing a definable trend. Generally, the structure of torrefied products tends to assume a composition more similar to conventional solid fuels (e.g. hydrocarbon structure of the coal) when increasing the severity of the process itself.
Plotting the $0 / \mathrm{C}$ atomic ratio (on $\mathrm{x}$-axis) and $\mathrm{H} / \mathrm{C}$ atomic ratio (on $\mathrm{y}$ axis) of each material torrefied at the different conditions, we obtain the van Krevelen diagrams. These diagrams highlight the structural changes related to the elemental composition variation and allow us to better interpret the effect of torrefaction treatment on the quality of biomasses to be used in combustion.

Figures 8 and 9 show the van Krevelen diagrams of both the materials object of the experimentation. In general, it can be seen that the experimental points are arranged along an imaginary line that originates from the characteristic values of the starting biomasses (upper right in the respective graphs) and gradually extends to lower values of $\mathrm{H} / \mathrm{C}$ and $\mathrm{O} / \mathrm{C}$ (toward the origin of the axes). The more extreme is the torrefaction process (>temperatures and/or $>$ time), the more enriched in carbon rather than oxygen and hydrogen are the torrefied products. As a consequence, their organic structure moves away from that of the original biomass and progressively tends to take on characteristics similar to that of coal, traditional solid fuel, acquiring at the same time the typical hydrophobic properties of non-polar hydrocarbons.

Table 4. Sunflower cake: analysis of torrefied products. Each torrefaction condition was tested in triplicate and the mean results are shown in the respective rows. Moreover, every parameter was analysed for each torrefied sample in duplicate (a third analysis repetition was not possible due to the small amount of sample available).

\begin{tabular}{|c|c|c|c|c|c|c|c|c|c|c|c|c|c|}
\hline $\begin{array}{l}\mathrm{T} \\
{ }^{\circ} \mathrm{C}\end{array}$ & $\begin{array}{c}\mathrm{t} \\
\mathrm{min}\end{array}$ & \multicolumn{2}{|c|}{$\%$ daf } & Ied & $\begin{array}{l}\text { HHV } \\
\text { MJ }\end{array}$ & $\mathrm{MJ} \times \mathrm{kg}^{-1}$ daf & C & & $\mathrm{af}^{\mathrm{N}}$ & 0 & $\mathrm{H} / \mathrm{C}$ & $\mathrm{O} / \mathrm{C}$ & $\begin{array}{c}\text { Ash } \\
\% \text { d.m. }\end{array}$ \\
\hline- & - & 100 & 100 & 1.00 & 23.7 & 22.1 & 55.17 & 7.80 & 3.47 & 33.56 & 1.68 & 0.46 & 4.71 \\
\hline 200 & 30 & 91.70 & 98.87 & 1.08 & 25.3 & 23.8 & 58.19 & 7.39 & 4.29 & 30.15 & 1.52 & 0.39 & 5.15 \\
\hline 200 & 60 & 90.69 & 97.08 & 1.07 & 25.2 & 23.7 & 59.16 & 7.55 & 3.70 & 29.59 & 1.52 & 0.38 & 5.20 \\
\hline 230 & 30 & 81.09 & 92.20 & 1.14 & 26.7 & 25.1 & 63.92 & 7.58 & 4.55 & 23.96 & 1.41 & 0.28 & 5.90 \\
\hline 230 & 60 & 78.18 & 92.41 & 1.18 & 27.7 & 26.1 & 63.74 & 7.62 & 4.08 & 24.57 & 1.42 & 0.29 & 5.80 \\
\hline 260 & 30 & 71.97 & 89.88 & 1.25 & 29.1 & 27.6 & 67.69 & 7.53 & 4.89 & 19.90 & 1.33 & 0.22 & 6.40 \\
\hline 260 & 60 & 64.08 & 85.27 & 1.33 & 31.0 & 29.4 & 71.48 & 7.64 & 4.75 & 16.14 & 1.28 & 0.17 & 7.30 \\
\hline
\end{tabular}

T, temperature; t, time; Ym, mass yields; Ye, energy yields; led, energy densification index; HHV, higher heating value; LHV, lower heating value; $\mathrm{C}$, carbon; $\mathrm{H}$, hydrogen; $\mathrm{N}$, nitrogen; $\mathrm{O}$, oxygen; $\mathrm{H} / \mathrm{C}$, hydrogen/carbon atomic ratio; $\mathrm{O} / \mathrm{C}$, oxygen/carbon atomic ratio.

Table 5. Energy characterisation of sunflower husks.

\begin{tabular}{|c|c|c|c|c|c|c|c|c|}
\hline $\begin{array}{c}\text { HHV } \\
M J \times \mathrm{kg}^{-1} \text { daf }\end{array}$ & LHV & C & H & & 0 & $\mathrm{H} / \mathrm{C}$ & $0 / C$ & $\begin{array}{l}\text { Ash } \\
\% \text { s.s. }\end{array}$ \\
\hline 23.2 & 21.6 & 56.60 & 7.55 & 1.65 & 34.19 & 1.59 & 0.45 & 3.90 \\
\hline
\end{tabular}

HHV, higher heating value; LHV, lower heating value; $\mathrm{C}$, carbon; $\mathrm{H}$, hydrogen; $\mathrm{N}$, nitrogen; $\mathrm{O}$, oxygen; $\mathrm{H} / \mathrm{C}$, hydrogen/carbon atomic ratio; $\mathrm{O} / \mathrm{C}$, oxygen/carbon atomic ratio.

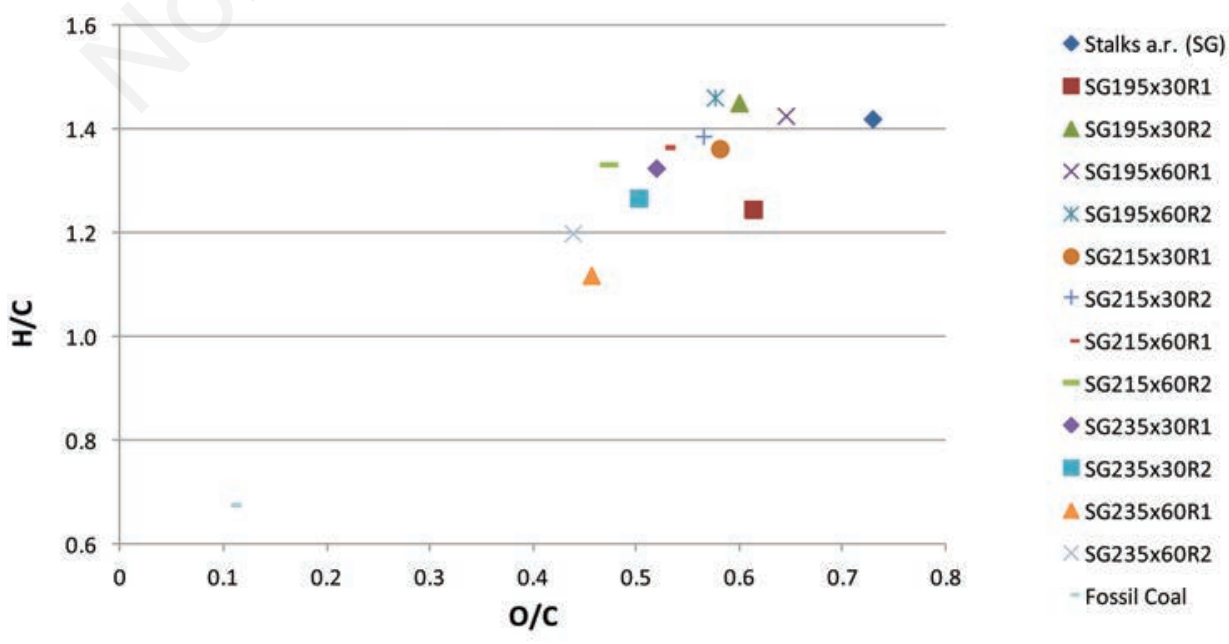

Figure 8. van Krevelen diagram obtained from the elemental characterisation of the raw and the torrefied sunflower stalks at the different conditions. Coal is reported for a comparison. (Source for the coal data: Phyllis/ECN, 1998). H/C, hydrogen/carbon ratio; O/C, oxygen/carbon ratio. 


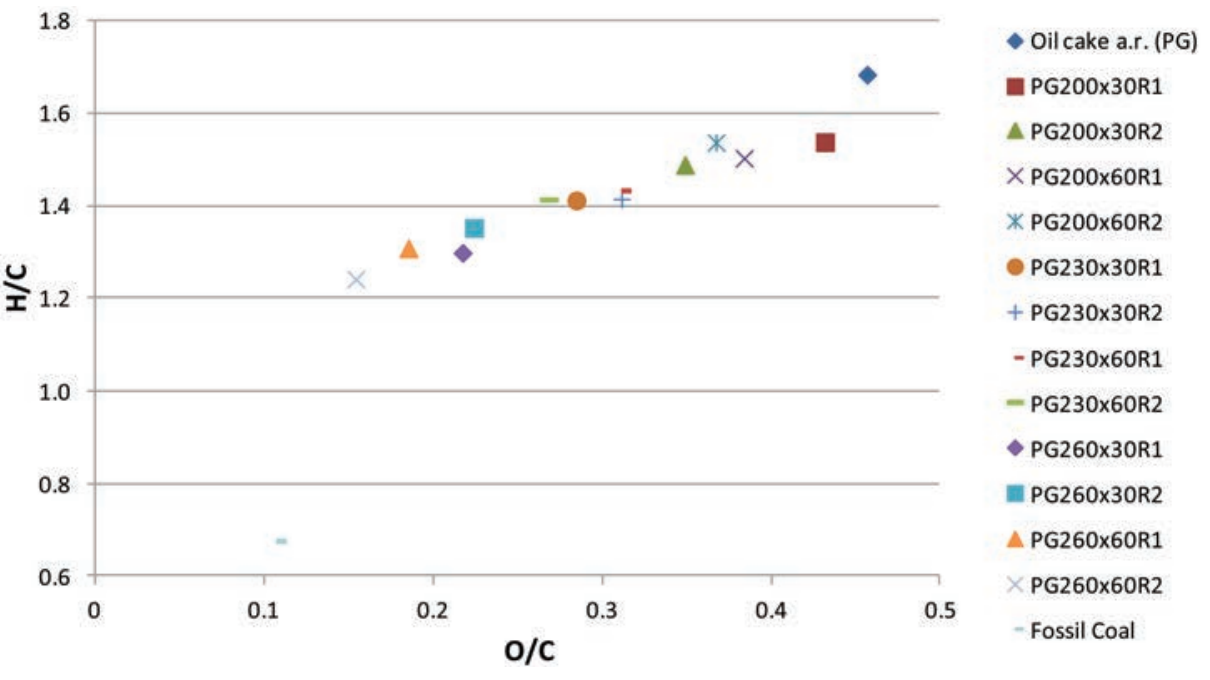

Figure 9. van Krevelen diagram obtained from the elemental characterisation of the raw and the torrefied sunflower cake at the different conditions. Coal is reported for a comparison. (Source for the coal data: Phyllis/ECN, 1998). H/C, hydrogen/carbon ratio; O/C, oxygen/carbon ratio.

\section{Conclusions}

The thermogravimetric analyses put in evidence the heterogeneity of the organic fraction which is basically lignocellulosic for sunflower stalks while it is much more complex in the press cake due to the presence of different matrices (such as the fatty component resituated from the seed oil extraction), as clearly shown by the DTG profile. Even the content of the inorganic fraction is quite variable in the different residual biomasses, with values ranging from $3.9 \%$ for sunflower husks to $11.6 \%$ for stalks. These values are significantly higher if compared with woody materials. The energy concentration, however, proves to be rather interesting, in particular for the sunflower press cake and husks.

The torrefaction process provides interesting qualitative improvements on all the biomasses treated. However, the price to be paid is related to the inevitable loss of mass and, as a whole, energy as well. This depends on the volatilisation of some organic compounds generated by the thermal degradation of macromolecules (hemicelluloses, cellulose and lignin). The different volatilisation kinetics of each biomass are clearly shown in the corresponding thermogravimetric profiles.

The torrefaction treatment reaches equilibrium when the standard quality of the products finds a compromise with the maximum performance of the treatment in terms of mass loss and energy concentration. This should be functional to the energy use to be done and, therefore, to the needs of the energy conversion system to be fuelled. The empirical study of the torrefaction process is a critical step that should be properly programmed according to the energy performances desired from the torrefied products and in order to identify the best conditions of the treatment. This approach becomes mandatory due to the structural and chemical variability of biomasses, even within the same product category. Materials with high moisture content and a molecular structure particularly rich in oxygen (and then with higher 0/C), such as sunflower stalks, when subjected to heat treatment, undergo more changes in mass but, at the same time, acquire significant benefits in terms of energy concentration.

In this perspective, from a technical point of view, it is better to employ the torrefaction with materials such as sunflower stalks while for sunflower cake and husks a better alternative, or even a direct ener- gy application, could be recommended. However, from a practical point of view, the torrefaction process is more feasible with residues produced in processing steps than in cultivation, due to logistic aspects.

\section{References}

Arias B., Pevida C., Fermoso J., Plaza M.G., Rubiera F., Pis J.J. 2008. Influence of torrefaction on the grindability and reactivity of woody biomass. Fuel Process. Technol. 89:169-75.

Chen W.H., Cheng W.Y., Lu K.M., Huang Y.P. 2011. An evaluation on improvement of pulverized biomass property for solid fuel through torrefaction. Appl. Energ. 88:3636-44.

Chen W.H., Kuo P.C. 2010. A study on torrefaction of various biomass materials and its impact on lignocellulosic structure simulated by a thermogravimetry. Energy 35:2580-6.

Grønli M.G., Várhegyi G., Di Blasi C. 2002. Thermogravimetric analysis and devolatilization kinetics of wood. Ind. Eng. Chem. Res. 41:4201-8.

Jenkins B.M., Baxter L.L., Miles T.R. Jr., Miles T.R. 1998. Combustion properties of biomass. Fuel Process. Technol. 54:17-46.

Li J., Brzdekiewicz A., Yang W.H., Blasiak W. 2012. Co-firing based on biomass torrefaction in a pulverized coal boiler with aim of $100 \%$ fuel switching. Appl. Energ. 99:344-54.

Uslu A., Faaij A.P.C., Bergman P.C.A. 2008. Pre-treatment technologies, and their effect on international bioenergy supply chain logistics. Techno-economic evaluation of torrefaction, fast pyrolysis and pelletisation. Energy 33:1206-23.

van der Stelt M.J.C., Gerhauser H., Kiel J.H.A., Ptasinski K.J. 2011. Biomass upgrading by torrefaction for the production of biofuels: a review. Biomass. Bioenerg. 35:3748-62.

Virmond E., De Sena R.F., Albrecht W. Althoff C.A., Moreira R.F., José H.J. 2012. Characterisation of agroindustrial solid residues as biofuels and potential application in thermochemical processes. Waste Manage. 32:1952-61.

Wu M.R., Schott D.L., Lodewijks G. Physical properties of solid biomass. 2011. Biomass Bioenerg. 35:2093-105. 